Original research article

\title{
Differences in carotid artery atherosclerosis between men and women in the early phase after ischemic event
}

\author{
Marta Skowronska ${ }^{a,}$, Anna Piorkowska ${ }^{a}$, Anna Czlonkowska ${ }^{a, b}$ \\ ${ }^{a}$ Institute of Psychiatry and Neurology, Sobieskiego 9, 02-957 Warsaw, Poland \\ ${ }^{\mathrm{b}}$ Department of Experimental and Clinical Pharmacology, Medical University of Warsaw, Poland
}

\section{A R T I C L E I N F O}

Article history:

Received 7 February 2017

Accepted 4 September 2017

Available online 20 September 2017

Keywords:

Carotid plaque morphology

Carotid ultrasound

Gender

Gray-scale median (GSM)

\begin{abstract}
A B S T R A C T
Objectives: There is little data about sex differences in carotid atherosclerosis in the early phase after an ischemic event. The aim of this study was to examine the carotid artery atherosclerosis differences between men and women in early phase after TIA or stroke. Methods: Consecutive patients with recent ischemic event, admitted during the first week after symptom onset were examined with ultrasound. Sex differences in degree of stenosis, number of plaques and plaque morphology were compared. Plaque morphology was assessed by gray-scale median (GSM), according to which lower values were associated with hemorrhagic/necrotic core indicating plaque instability.

Results: Of the 316 patients with ischemic events, 196 (50.5\% male) entered the study. Men had more often moderate as well as severe ipsilateral carotid stenosis $(12.1 \%$ vs $7.2 \%$ for moderate and $12.1 \%$ vs $2.1 \%$ for severe; $p=0.024$ ). Men had more often the largest plaque hypoechogenic contralateral (62.6\% vs $37.1 \%, p=0.0008)$, but not ipsilateral. Men had 3 or more hypoechogenic plaques $(24.2 \%$ vs $4.1 \%, p=0.0001 ; 17.2 \%$ vs $4.1 \%, p<0.0001)$ both ipsi and contralateral respectively. Male sex was a risk factor for having 3 or more ipsilateral hypoechogenic plaques $(p=0.002, \mathrm{OR}=20$ CI 95\% [5.5-75].

Conclusions: Men had more often carotid stenosis and higher number of hypoechogenic plaques.
\end{abstract}

() 2017 Polish Neurological Society. Published by Elsevier Sp. z o.o. All rights reserved.

\section{Introduction}

Women are at lower risk of stroke and appear to benefit less from carotid endarterectomy (CEA) than men [1]. The exact causes or mechanisms of the sex differences in stroke incidence rate and CEA outcomes are not fully understood [2]. The explanation might be the distribution and morphology of carotid plaques. Women are less likely to have carotid disease [1], whereas men were shown to have larger plaque area [3] and "higher-risk" plaques; for example, ones with

\footnotetext{
* Corresponding author at: Institute of Psychiatry and Neurology, $2^{\text {nd }}$ Department of Neurology, Poland.

E-mail addresses: marta.ms@simplusnet.pl (M. Skowronska), apiork@wp.pl (A. Piorkowska), czlonkow@ipin.edu.pl (A. Czlonkowska). http://dx.doi.org/10.1016/j.pjnns.2017.09.002

0028-3843/@ 2017 Polish Neurological Society. Published by Elsevier Sp. z o.o. All rights reserved.
} 
thin/ruptured fibrous cap and lipid-rich/necrotic core or intraplaque hemorrhage [2]. Faster plaque healing may also account for the reduced benefit of CEA in women [4]. However, there is little data regarding sex differences in carotid atherosclerosis in the early phase after an ischemic event.

High-resolution B-mode ultrasound is a valid and reproducible noninvasive tool for visualization and quantification of carotid atherosclerosis. In addition to the degree of carotid stenosis, plaque properties are also important in vascular disease [5,6]. Dark and low-echogenic (echolucent) plaques on ultrasound are believed to be more "vulnerable" for causing vascular events [7]. A computerized approach using gray-scale median (GSM) measurement is considered to be a more objective and quantitative method for plaque assessment than visual analysis itself, and this approach has been used in many studies [8-12]. The GSM approach can be employed to predict instability of both asymptomatic and symptomatic plaques $[13,14]$.

The aim of this study was to compare carotid plaques between men and women using GSM method in the early phase after an ischemic event.

\section{Methods}

\subsection{Patients}

The study cohort consisted of consecutive patients admitted with cerebral ischemic event (stroke or transient ischemic attack [TIA]) during the first week after symptoms onset. Carotid ultrasound was performed within $48 \mathrm{~h}$ from admission and only patients with at least one carotid plaque (ipsi - or contralateral) entered the study. Information regarding history of hypertension (systolic blood pressure $>140 \mathrm{~mm} \mathrm{Hg}$ and diastolic blood pressure $>90 \mathrm{~mm} \mathrm{Hg}$ ), atrial fibrillation, coronary heart disease (diagnosed by invasive or noninvasive methods), peripheral artery disease (PAD) - diagnosed before or walking distance less than $200 \mathrm{~m}$, previous myocardial infarct (MI) - only diagnosed and treated, total cholesterol level $>200 \mathrm{mg} \%$ and diabetes mellitus was collected.

\subsection{Ultrasonography}

High-resolution B-mode ultrasonography was performed with a duplex scanner (GE VIVID 7) equipped with a $7.5-10 \mathrm{MHz}$ linear array transducer. The far and near walls of the right and left common carotid artery (CCA), bifurcation, and internal carotid artery (ICA) were scanned for the presence of plaques. A plaque was defined as a local thickening of the intima $>1.5 \mathrm{~mm}$. For each plaque a still image was recorded. B-mode images were digitized and transferred to a personal computer and further steps were performed in Adobe Photoshop. Plaque echogenicity was assessed by GSM using the histogram function. GSMs of the lumen and adventitia were used as reference structures. Each plaque was then outlined with the Lasso tool, and the cropped image was standardized against the lumen and adventitia - Fig. 1. Since plaques with large calcifications presented with the highest GSM values, and those with large hemorrhagic areas or with predominant necrotic core exhibited the lowest values [15], and GSM $<50$ was associated with a necrotic core, we decided to stratify plaques into 2 groups; $\leq 50 \mathrm{GSM}$, and $>50 \mathrm{GSM}$.

The measurement of the carotid plaque area was used to choose the largest plaque. First the best plane for measurement was found by panning around the artery until the view showing the largest extent of that plaque was obtained. Then,

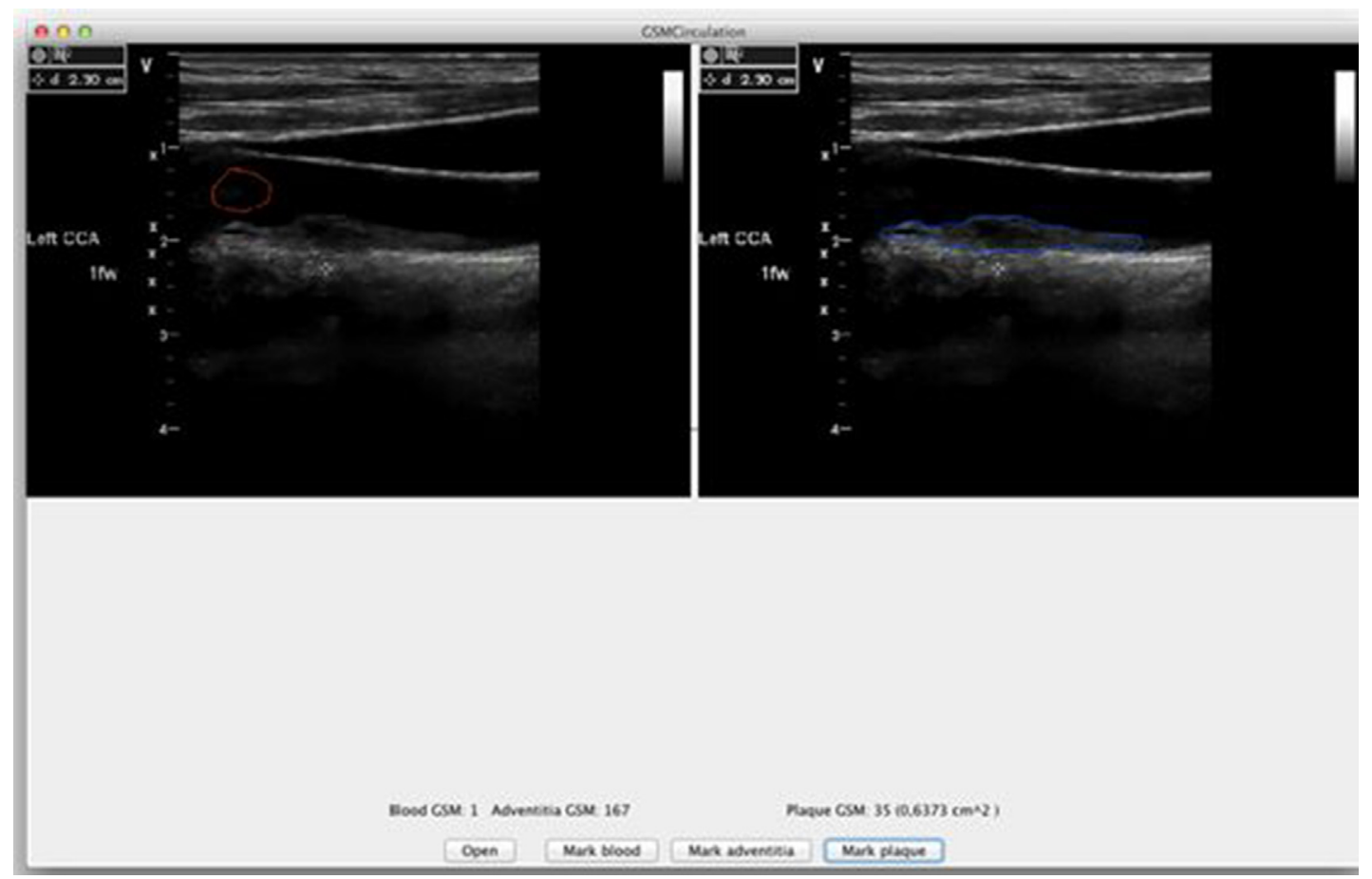

Fig. 1 - Images showing a carotid plaque. Measurements are performed with vessel lumen as reference for gray-scale median (GSM). 
images of magnified longitudinal view of each plaque seen in the right and left common and internal carotid arteries were captured. Finally, measurements were performed automatically after manually encircling the circumference of the plaque [16]. Stenosis was measured by Doppler peak flow velocity in the range used in the ultrasound lab, calibrated against angiography. The interobserver coefficients of variability were $4.0 \%$ for the performing sonographer (AP).

\subsection{Statistical analysis}

Men and women were compared for collected variables: risk factors and plaque characteristics. For parametric variables $\chi^{2}$ was used and for nonparametric Wilcoxon test was performed. The main objective was to investigate the relation between sex and plaque GSM in multivariate logistic regression model. Generalized linear model (GLM) [17] was chosen as the basic model. The optimal model from GLM family was chosen based on the Akaike Information Criterion (AIC) and the deviance was examined to verify whether the model has been adequate. Selected GLM model was composed of the Gaussian error and the log-link function. The calculations were performed using SAS system rel.13.2. The results were considered statistically significant at $p<0.05$.

\section{Results}

\subsection{Patients characteristics}

During the study period 316 patients with ischemic event were admitted within the first week after the symptoms onset. Of these, 268 (132 men) were diagnosed with ischemic stroke and 48 (28 men) with TIA. In 53 cases carotid ultrasound was not performed due to severe stroke, poor general condition, cardiac or respiratory failure. Carotid ultrasound was performed in 263 cases and 67 patients were free of carotid plaques. Finally 196 patients with ischemic event entered the study. Baseline characteristics are presented in Table 1. Men were 5 years younger $(p=0.0003)$ and suffered from peripheral artery disease and high cholesterol level more often than women. Atrial fibrillation was more common in women than men $(p=0.0075)$. The differences in distribution of other risk factors were not significant, although they were diagnosed more often in men.

\subsection{Plaque characteristics}

Differences between men and women are presented in Table 2. Men had more often moderate and severe ipsilateral carotid stenosis and any type of stenosis contralateral. Men had higher number of hypoechogenic plaques both ipsilateral and contralateral. There was a trend among men to have more often the largest plaque hypoechogenic ipsilateral $(p=0.07)$, but the difference between men and women was statistically significant for contralateral plaques.

In multivariate logistic regression models, male sex was a risk factor for having 3 or more ipsilateral plaques $\leq 50 \mathrm{GSM}$ $(p=0.002, \mathrm{OR}=20 \mathrm{CI} 95 \%$ [5.5-75].

\section{Discussion}

Assessment of atherosclerosis is difficult as many different parameters like stenosis, plaque morphology and plaque area play role in symptomatic disease. Plaque morphology studies are usually conducted in patients with large artery disease, were pathogenesis of ischemic event is due to so-called vulnerable plaque and stenosis itself. Some studies show that presence of plaques in carotid arteries increases the risk of any type of stroke [18], and plaque features like intraplaque hemorrhage or thin/ruptured fibrous cap are not related to ipsilateral infarct in moderate stenotic patients [19]. Taking these observations into account, we decided to include all the patients with an ischemic event and both sides ipsi- and contralateral for the analysis of gender differences. Moreover, time plays an important role in the plaque assessment, as plaques change over time. There is evidence for a healing process of plaque ruptures, especially in the coronary arteries [20], but also in the carotid arteries [21-23]. Faster plaque healing was considered as a plausible explanation for the time reduced benefit of CEA in women. Because carotid plaques change over time we included only patients admitted during the first week after an ischemic event and ultrasound examination was performed in the first $48 \mathrm{~h}$ from admission.

Table 1 - Baseline characteristics of the study group.

\begin{tabular}{llll} 
Risk factors & Women, $n=97$ & Men, $n=99$ & $p$ value \\
\hline Age & $75.9($ range $51-92)$ & $70.4($ range $48-89)$ & 0.0003 \\
Hypetension & $87(89.7 \%)$ & $88(88.9 \%)$ & 0.856 \\
Atrial Fibrillation & $34(35 \%)$ & $18(18.2 \%)$ & 0.0075 \\
Coronary heart disease & $37(38 \%)$ & $44(44 \%)$ & 0.388 \\
Myocardial infarction & $15(15.5 \%)$ & $27(27.3 \%)$ & 0.055 \\
Diabetes & $18(18.6 \%)$ & $21(21.2 \%)$ & 0.721 \\
Peripheral artery disease & $2(2.1 \%)$ & $15(15.2 \%)$ & 0.0013 \\
Lipid level alternation & $50(51.6 \%)$ & $68(68.7 \%)$ & 0.019 \\
Smoking & $18(18.6 \%)$ & $29(29.6 \%)$ & 0.072 \\
Antiplatelet treatment & $36(37.1 \%)$ & $35(35.4 \%)$ & 0.631 \\
Statins & $29(29.9 \%)$ & $31(31.3 \%)$ & 0.877 \\
\hline$p<0.05$ & & &
\end{tabular}


Table 2 - Plaque differences between men and women.

\begin{tabular}{|c|c|c|c|}
\hline & Women, $n=97$ & Men, $n=99$ & $p$ value \\
\hline Ipsilateral stenosis & & & 0.024 \\
\hline No plaques & $8(8.3 \%)$ & $7(7.1 \%)$ & \\
\hline$<50 \%$ & $80(82.5 \%)$ & $68(68.7 \%)$ & \\
\hline $50-69 \%$ & $7(7.2 \%)$ & 12 (12.1\%) & \\
\hline 70-99\% & $2(2.1 \%)$ & 12 (12.1\%) & \\
\hline Contralateral stenosis & & & 0.034 \\
\hline No plaques & $20(20.6 \%)$ & $8(8.1 \%)$ & \\
\hline$<50 \%$ & $68(70.1 \%)$ & $76(76.8 \%)$ & \\
\hline $50-69 \%$ & $8(8.3 \%)$ & $15(15.2 \%)$ & \\
\hline 70-99\% & $1(1 \%)$ & 0 & \\
\hline Ipsilateral largest plaque GSM & & & 0.07 \\
\hline no plaques & $8(8.3 \%)$ & $8(8.1 \%)$ & \\
\hline$>50$ & $43(44.3 \%)$ & $29(29.3 \%)$ & \\
\hline$\leq 50$ & $46(47.4 \%)$ & $62(62.6 \%)$ & \\
\hline Contralateral largest plaque GSM & & & 0.0008 \\
\hline No plaques & 19 (19.6\%) & $7(7.1 \%)$ & \\
\hline$>50$ & $42(43.3 \%)$ & $30(30.3 \%)$ & \\
\hline$\leq 50$ & $36(37.1 \%)$ & $62(62.6 \%)$ & \\
\hline Ipsilateral numer of plaques $\leq 50$ & & & 0.0001 \\
\hline No plaques & $42(43.3 \%)$ & $26(26.3 \%)$ & \\
\hline 1 & 37 (38.1\%) & 30 (30.3\%) & \\
\hline 2 & $14(14.4 \%)$ & 19 (19.2\%) & \\
\hline 3 and more & $4(4.1 \%)$ & $24(24.2 \%)$ & \\
\hline Contralateral numer of plaques $\leq 50$ & & & $<0.0001$ \\
\hline No plaques & $48(49.5 \%)$ & $24(24.2 \%)$ & \\
\hline 1 & $34(35.1 \%)$ & $34(34.3 \%)$ & \\
\hline 2 & $11(11.3 \%)$ & $24(24.2 \%)$ & \\
\hline 3 and more & $4(4.1 \%)$ & $17(17.2 \%)$ & \\
\hline
\end{tabular}

Our study revealed that men had stenosis more often than women, both ipsi - and contralateral. This is consistent with another large carotid atherosclerosis study of symptomatic patients, which shows that men were more likely to have severe carotid atherosclerosis than women [24]. On the contrary, in the population studies of both symptomatic and asymptomatic patients, men had less carotid stenosis $[3,25]$.

Most of the data shows that men tend to be at higher risk for having vulnerable plaques [2,3,26-29], however there is some evidence for the contrary correlation [30] or age related changes with no sex differences [31]. In this study we have also shown the protective role of female gender. In general men had a higher number of hypoechogenic plaques and the largest hypoechogenic plaque both ipsi - and contralateral.

Sex hormones play a crucial protective role in women, affecting endothelial function, development of cardiovascular risk factors and plaque stabilization properties [3]. Plaque stabilization is probably reached by anti-inflammatory effects of estrogen modulated by its antioxidant and antiapoptotic effects [32]. In coronary plaques this effect declines faster over time and postmenopausal women have similar plaques to men and differ from women in childbearing age [33]. Studies conducted on carotid plaques $[2,18,27,29]$, as well as our study, show protective role of female gender in postmenopausal women. Carotid endarterectomy plaques obtained from women are less inflammatory $[27,29]$ with lower macrophage and interleukin-8 content and with greater smooth muscle and collagen [34]. It is also possible, that due to premenopausal estrogen effect, women are exposed to cardiovascular risk factors shorter than men [35]. This observation leads to conclusion of potential menopause hormone therapy providing cardiovascular benefits but the role of hormonal therapy remains unproven [36]. Not only the plaque morphology is different in men and women, but also the degree of stenosis and the number of plaques. There is data about differences in bifurcation anatomy between men and women. The outflow to inflow area ratio is bigger in women, and relative to the CCA and external carotid artery (ECA), women have larger ICAs than men. A proportion of a pulse wave arriving at a bifurcation is reflected, and the higher the degree of reflection, the more sheer stress will develop locally. An increase in local pressure can lead to endothelial damage and favor plaque development. This finding could be responsible for sex differences in plaque distribution and prevalence [35,37].

In conclusions: we found that men had moderate to severe stenosis, the higher number of hypoechogenic plaques and the largest hypoechogenic plaque more often than women. Male sex is an independent risk factor for having 3 or more hypoechogenic ipsilateral plaques. Differences between men and women are probably due to lasting protective effect of sex hormones.

\section{Conflict of interest}

None declared. 


\section{Acknowledgement and financial support}

None declared.

\section{RE F E RENCES}

[1] Alamowitch S, Eliasziw M, Barnett HJ. The risk and benefit of endarterectomy in women with symptomatic internal carotid disease. Stroke 2005;36:27-31.

[2] Ota H, Reeves MJ, Zhu DC, Majid A, Collar A, Yuan C, et al. Sex differences in patients with asymptomatic carotid atherosclerotic plaque. In Vivo 3.0-T Magnetic Resonance Study. Stroke 2010;41:1630-5.

[3] Iemolo F, Martiniuk A, Steinman DA, Spence JD. Sex differences in carotid plaque and stenosis. Stroke 2004;35:477-81.

[4] Rothwell PM, Eliasziw M, Gutnikov SA, Warlow CP, Barnett HJ. Sex difference in the effect of time from symptoms to surgery on benefit from carotid endarterectomy for transient ischemic attack and nondisabling stroke. Stroke 2004;35:2855-61.

[5] Joakimsen O, Bønaa KH, Stensland-Bugge E, Jacobsen BK. Age and sex differences in the distribution and ultrasound morphology of carotid atherosclerosis. The Troms $\varnothing$ Study. Arteriosc Thromb Vasc Biol 1999;19:3007-13.

[6] Kwee RM, van Oostenbrugge RJ, Hofstra L, Teule GJ, van Engelshoven JMA, Mess WH, et al. Identifying vulnerable carotid plaques by noninvasive imaging. Neurology 2008;70:2401-9.

[7] Mathiesen EB, Bønaa KH, Joakimsen O. Echolucent plaques are associated with high risk of ischemic cerebrovascular events in carotid stenosis: the Troms $\varnothing$ Study. Circulation 2001;103:2171-5.

[8] Tegos TJ, Sabetai MM, Nicolaides AN, Pare G, Elatrozy TS, Dhanjil S, et al. Comparability of the ultrasonic tissue characteristics of carotid plaques. J Ultrasound Med 2000;19:399-407.

[9] El-Barghouty N, Geroulakos G, Nicolaides A, Androulakis A, Bahal V. Computer-assisted carotid plaque characterization. Eur J Vasc Endovasc Surg 1995;9:389-93.

[10] Matsagas MI, Vasdekis SN, Gugulakis AG, Lazaris A, Foteinou M, Sechas MN. Computer-assisted ultrasonographic analysis of carotid plaques in relation to cerebrovascular symptoms, cerebral infarction, and histology. Ann Vasc Surg 2000;14:130-7.

[11] Gronholdt ML, Nordestgaard BG, Schroeder TV, Vorstrup S, Sillesen H. Ultrasonic echolucent carotid plaques predict future strokes. Circulation 2001;104:68-73.

[12] El-Barghouty NM, Levine T, Ladva S, Flanagan A, Nicolaides A. Histological verification of computerised carotid plaque characterisation. Eur J Vasc Endovasc Surg 1996;11:414-6.

[13] Hashimoto H, Tagaya M, Niki H, Etani H. Computer-assisted analysis of heterogeneity on B-Mode imaging predicts instability of asymptomatic carotid plaque. Cerebrovasc Dis 2009;28:357-64.

[14] Ruiz-Ares G, Fuentes B, Martínez-Sánchez P, MartínezMartínez M, Díez-Tejedor E. Utility of the assessment of echogenicity in the identification of symptomatic carotid artery atheroma plaques in ischemic stroke patients. Cerebrovasc Dis 2011;32:535-41.

[15] Sztajzel R, Momjian S, Momjian-Mayor I, Murith N, Djebaili K, Boissard G, et al. Stratified Gray-Scale Median analysis and color mapping of the carotid plaque. Correlation with endarterectomy specimen histology of 28 patients. Stroke 2005;36:741-5.

[16] Spence JD, Eliasziw M, DiCicco M, Hackam DG, Galil RT, Lohmann T. Carotid plaque area: a tool for targeting and evaluating vascular preventive therapy. Stroke 2002;33:2916-22.

[17] Vittinghoff E, Glidden D, Shiboski S, McCulloch C. Regression methods in biostatistics. NY: Springer; 2012.

[18] Hollander M, Bots ML, Del Sol AI, Koudstaal PJ, Witteman JC, Grobbee DE, et al. Carotid plaques increase the risk of stroke and subtypes of cerebral infarction in asymptomatic elderly: the Rotterdam Study. Circulation 2002;105:2872-7.

[19] de Rotte AAJ, Truijman MTB, van Dijk AC, Liem MI, Schreuder FHBM, Anja G, et al. Plaque components in symptomatic moderately stenosed carotid arteries related to cerebral infarcts. The Plaque at RISK Study. Stroke 2015;46:568-71.

[20] Burke AP, Kolodgie FD, Farb A, Weber DK, Malcom GT, Smialek J, et al. Healed plaque ruptures and sudden coronary death: evidence that subclinical rupture has a role in plaque progression. Circulation 2001;103:934-40.

[21] Peeters W, Hellings WE, de Kleijn DPV, de Vries JP, Moll FL, Vink A, et al. Carotid atherosclerotic plaques stabilize after stroke: insights into the natural process of atherosclerotic plaque stabilization. Arteriosc Thromb Vasc Biol 2009;29:128-33.

[22] Redgrave JN, Lovett JK, Gallagher PJ, et al. Histological assessment of 526 symptomatic carotid plaques in relation to the nature and timing of ischemic symptoms: the Oxford Plaque Study. Circulation 2006;113:2320-8.

[23] Virmani R, Finn AV, Kolodgie FD. Carotid plaque stabilization and progression after stroke or TIA. ArterioscThromb Vasc Biol 2009;29:3-6.

[24] Kapral MK, Ben-Yakov M, Fang J, Gladstone DJ, Saposnik G, Robertson A, et al. Gender differences in carotid imaging and revascularization following stroke. Neurology 2009;73:1969-74.

[25] Johnsen SH, Mathiesen EB, Joakimsen O, Stensland E, Wilsgaard T, Lochen ML, et al. Carotid atherosclerosis is a stronger predictor of myocardial infarction in women than in men. A 6-year follow-up study of 6226 persons: the Troms $\varnothing$ Study. Stroke 2007;38:2873-80.

[26] Sangiorgi G, Roversi S, Zoccai GB, Modena MG, Servadei F, Ippoliti A, et al. Sex-related differences in carotid plaque features and inflammation. J Vasc Surg 2013;57:338-44.

[27] Wendorff C, Wendorff H, Pelisek J, Tsantilas P, Zimmermann A, Zernecke A, et al. Carotid plaque morphology is significantly associated with sex, age and history of neurological symptoms. Stroke 2015;46:3213-9.

[28] Singh N, Moody AR, Zhang B, Kaminski I, Kapur K, Chiu S, et al. Age-specific sex differences in magnetic resonance imaging-depicted carotid intraplaque haemorrhage. Stroke 2017;48. http://dx.doi.org/10.1161/STROKEAHA.117.017877.

[29] Wendorff C, Wendorff H, Kuehnl A, Tsantilas P, Kallmayer M, Eckstein HH, et al. Impact of sex and age on carotid plaque instability in asymptomatic patients-results from the Munich Vascular Biobank. Vasa 2016;45:411-6.

[30] Van den Oord SCH, van der Burg J, Akkus Z, Bosch JG, van Domburg RT, Sijbrands EJG, et al. Impact of gender on the density of intraplaque neovascularization: a quantitative contrast-enhanced ultrasound study. Atherosclerosis 2014;233:461-6.

[31] van Oostrom O, Velema E, Schoneveld AH, de Vries JP, de Bruin P, Seldenrijk CA, et al. Age-related changes in plaque composition: a study in patients suffering from carotid artery stenosis. Cardiovasc Pathol 2005;14:126-34.

[32] Nofer JR. Estrogens and atherosclerosis: insights from animal models and cell systems. J Mol Endocrinol 2012;48: R13-29. http://dx.doi.org/10.1530/JME-11-0145 
[33] Burke AP, Farb A, Malcom G, Virmani R. Effect of menopause on plaque morphologic characteristics in coronary atherosclerosis. Am Heart J 2001;141(2 Suppl.):S58-62.

[34] Hellings WE, Pasterkamp G, Verhoeven BA, De Kleijn DP, De Vries JP, Seldenrijk KA, et al. Gender-associated differences in plaque phenotype of patients undergoing carotid endarterectomy. J Vasc Surg 2007;45:289-96. http://dx.doi. org/10.1016/j.jvs.2006.09.051. discussion 296
[35] Tromba L, Tartaglia F, Blasi MD S, Giuliani A, Carbotta S, Kiltzanidi D, et al. Is carotid stenosis in women a genderrelated condition? J Women's Health 2016;25:348-54.

[36] Bhavnani BR, Strickler RC. Menopausal hormone therapy. J Obstet Gynaecol Can 2005;27:137-62

[37] Schulz UGR, Rothwell PM. Sex differences in carotid bifurcation anatomy and the distribution of atherosclerotic plaque. Stroke 2001;32:1525-31. 